\title{
MODELLING OF HEALTH MONITORING SIGNALS AND DETECTION AREAS FOR AEROSPACE STRUCTURES
}

\author{
Jan Šplíchal ${ }^{1}$, Jiří Hlinka ${ }^{1}$ \\ ${ }^{1}$ Institute of Aerospace Engineering \\ Brno University of Technology \\ Technická 2, 61669 Brno, Czech Republic \\ Jan.Splichal@vutbr.cz
}

Keywords: Structural health monitoring (SHM), Ultrasonic guided waves (UGW), Finite element methods (FEM), damage detection

\begin{abstract}
This paper is focused on Structural Health Monitoring (SHM) for aerospace use. It analyses the performance of commercially available finite element (FE) software packages for the simulation of propagation of ultrasonic guided waves (UGW) in typical aerospace structures. The purpose of the research is to support activities leading to the introduction of UGW based health monitoring on aerospace structures, as well as to support the design of future structures with integrated health monitoring. Activities are demonstrated on panels with growing complexity (adding different materials, sensors, damage types etc.). FE simulations are used to identify "detection areas" of UGW sensors. This output can be directly applied to the design of future aerospace structures with an integrated SHM system (to ensure the proper planning of the placement of UGW sensors).
\end{abstract}

\section{INTRODUCTION}

Detection of damage and the prevention of structural failures are critically important issues in aerospace. A significant amount of research work is dedicated to maintenance procedures, including new technologies for damage detection. Today, aviation is dependent a lot on "traditional" inspections, visual or utilizing non-destructive testing methods (NDT). New technologies connected under the title Structural Health Monitoring (SHM) are under development, and these have a significant chance of complimenting the abovementioned methods. SHM methods may also be successfully used in locations that are hard to reach by traditional methods. Many research papers, including for example [1],[2], can be used as summarized information source for SHM technologies.

Ref. [1] states that "SHM is the integration of sensing and possibly also actuation devices to allow the loading and damaging conditions of a structure to be recorded, analysed, localised and predicted in a way that non-destructive testing becomes an integral part of the structure".

Apart from operational loads monitoring, which can be found on operational aircraft, SHM technologies were tested, for example, for aircraft landing gear structure monitoring (acoustic emission, see ref. [3]), or for tail structure monitoring on Cessna T-303 (acoustic emission, see ref. [4]). AISHA FP6 EU project did study damage detection by Lamb waves (UGW). Within this research, Lamb waves were applied as SHM means on structural parts of MI-8, EC135 helicopters and A320 aircraft 
(see ref. [5]). Also AIRBUS has presented that according to its long-term vision, all new aircraft will fly with distributed fibre Bragg grating (FBG) optical sensors, see ref. [6].

This paper will discuss the contribution to one target SHM technology, utilizing UGW (ultrasonic guided waves) signals to detect damage in structures made of metal or composite materials. UGW technology (sometimes also called Lamb waves) is applicable to detect a wide range of damage, the most important being particularly fatigue damage (with growing cracks) and impact damage. Attention in this paper will be given to application on modern composite structures, where detection of structural damage is an often challenging and difficult task. UGW can be used to obtain on-line monitoring and to reduce maintenance costs. However, propagation of the complexity of waves typically limits current applications to the laboratory. Therefore, a significant amount of work needs to be done especially towards understanding propagation and the response of waves on different conditions and damage types. To speed up this process, and to save a significant amount of resources, computer based modelling can be used to support research and development tests. The paper will present experience gained during the research of possible modelling options for UGW modelling using finite element methods. The achieved results strongly suggest that it may be possible to model Lamb waves propagation in the structure with reasonable precision, therefore FEM may be used to find, for example, expected detection areas of sensors

\section{EARLY FE MODEL - SENSOR SYSTEM FOR UGW IN FEM SOFTWARE}

Application of Finite Element (FE) modelling may significantly reduce development costs during the development of new structural components with an integrated SHM system. Proper sensor placement and distances between sensors can be defined well before the production of a structural component. In addition, FE modelling enables the application of optimization algorithms for optimized sensor placement. This can help to secure health monitoring function with a certain level of reliability also in the case of the failure of individual sensors.

This paper aims to describe the complete procedure from less complex models applied on metal structures, to more complex models applied on composite structures. The first FE simulations of UGW signals were done on the model of a metal panel. The panel included one PZT actuator and one PZT sensor (PZT- Lead Zirconate Titanate Piezoelectric Sensor/Actuator). The simulation aimed to verify the signal propagation velocity, as well as the shape of the signal (wave) for actuator signal frequencies around $100 \mathrm{kHz}$. Comparison of FEM output with analytical calculation using "WAVEFORM REVEALER 3 - Laboratory for active Materials and Smart Structure"ref. [7] confirmed similar results. Therefore, the possibility of using modern FE software for UGW simulation was confirmed on the basic level. The procedure is further described in detail.

\subsection{FEM software}

For UGW simulations, the following commercial FEM software package was tested: MSC.Patran/MSC.Dytran, where MSC.Patran served only as pre and post processor (preparation of the FE model and visualization of results). The software package is dedicated to the analysis of fast processes and large deformations. MSC.Dytran is an explicit finite element analysis (FEA) solution for simulating short-duration events such as impact and crash, and to analyse the complex nonlinear behaviour that structures undergo during these events ref. [8].

For comparison purposes, selected models were evaluated also using MSC.Nastran Explicit Nonlinear (SOL 700) with similar results, as in the case of MSC.Dytran. Within this paper, all further described FE models and results were prepared using MSC.Dytran. 


\subsection{Panel and sensor}

To analyses UGW propagation, the panel with dimensions 800x600 [mm] and thickness 1 [mm] (Fig. 1) was used. Aluminum-2124-T851 material was applied, with characteristics summarized in Table 1. Sensors placed on the panel were NAC 2002 type on ref. [9]. Estimated material properties for sensors are shown in Table 2. Material properties of the sensor were based on ref. [10]

\begin{tabular}{|l|l|l|}
\hline Young's modulus & $E$ & $73100[\mathrm{MPa}]$ \\
\hline Poisson's ratio & $\mu$ & 0.33 \\
\hline Mass density & $\rho$ & $2780\left[\mathrm{kgm}^{-3}\right]$ \\
\hline
\end{tabular}

Table 1: Material: Aluminium - 2124 - T851

\begin{tabular}{|l|l|l|}
\hline Young's modulus & $\mathrm{E}$ & $32000[\mathrm{MPa}]$ \\
\hline Poisson's ratio & $\mu$ & 0.33 \\
\hline Mass density & $\rho$ & $7850\left[\mathrm{kgm}^{-3}\right]$ \\
\hline
\end{tabular}

Table 2 : Material: Sensor - NCE51 ref. [10]

\subsection{Comparative Analytical Methods}

FE models applied within this research required from an early stage of work verification based on practical test results and proven analytical methods. Therefore, comparisons with several research works published by other authors was done on simple models, see for example ref.[11].

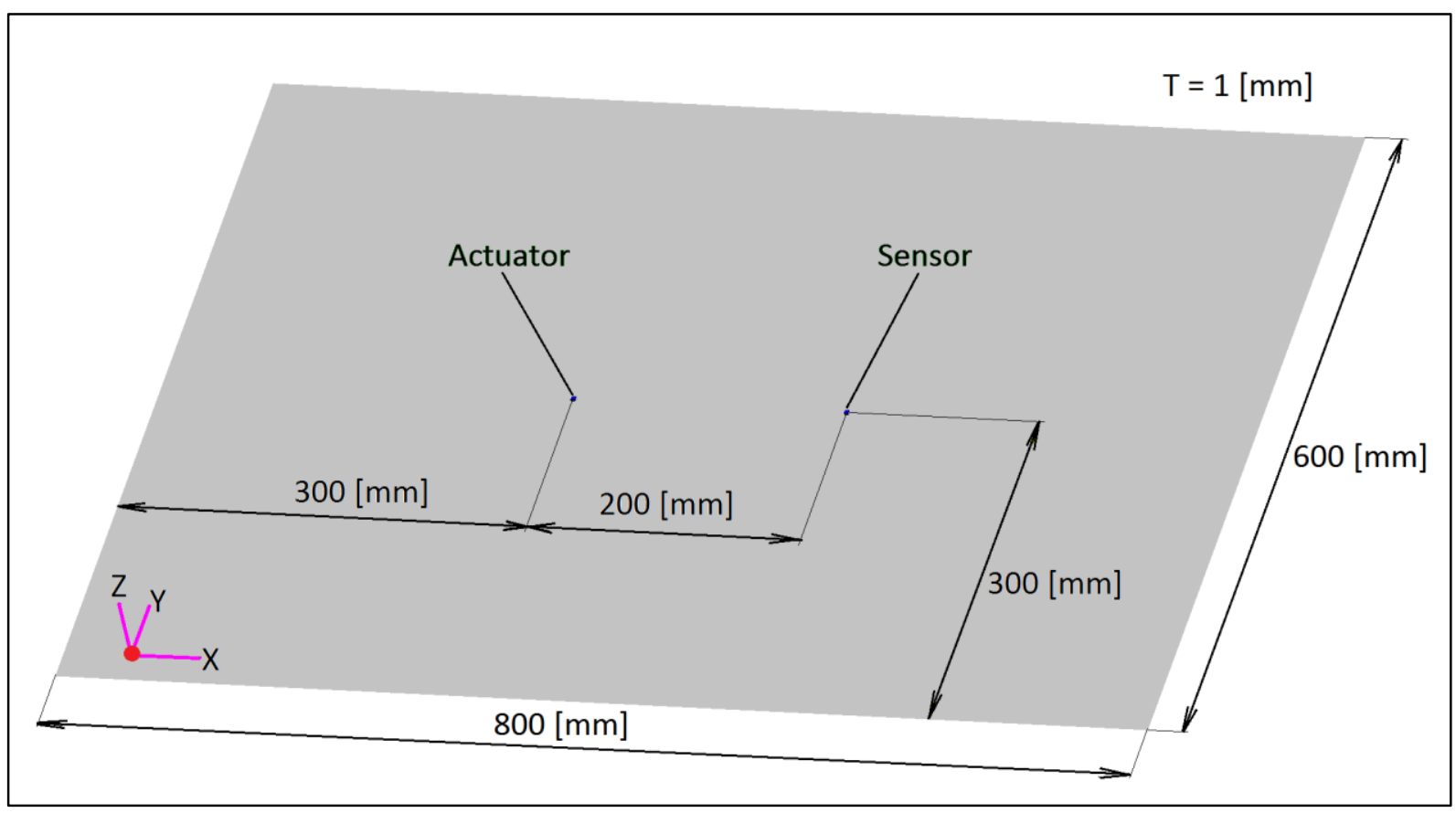

Figure 1: Panel with coordinate system

In addition, to verify results for simple models (panel with one actuator and one sensor), analytical software developed at the University of South Carolina was used: Laboratory for active Materials and Smart Structure (LAMSS) - Program WAVE FORM REVEALER 3. 


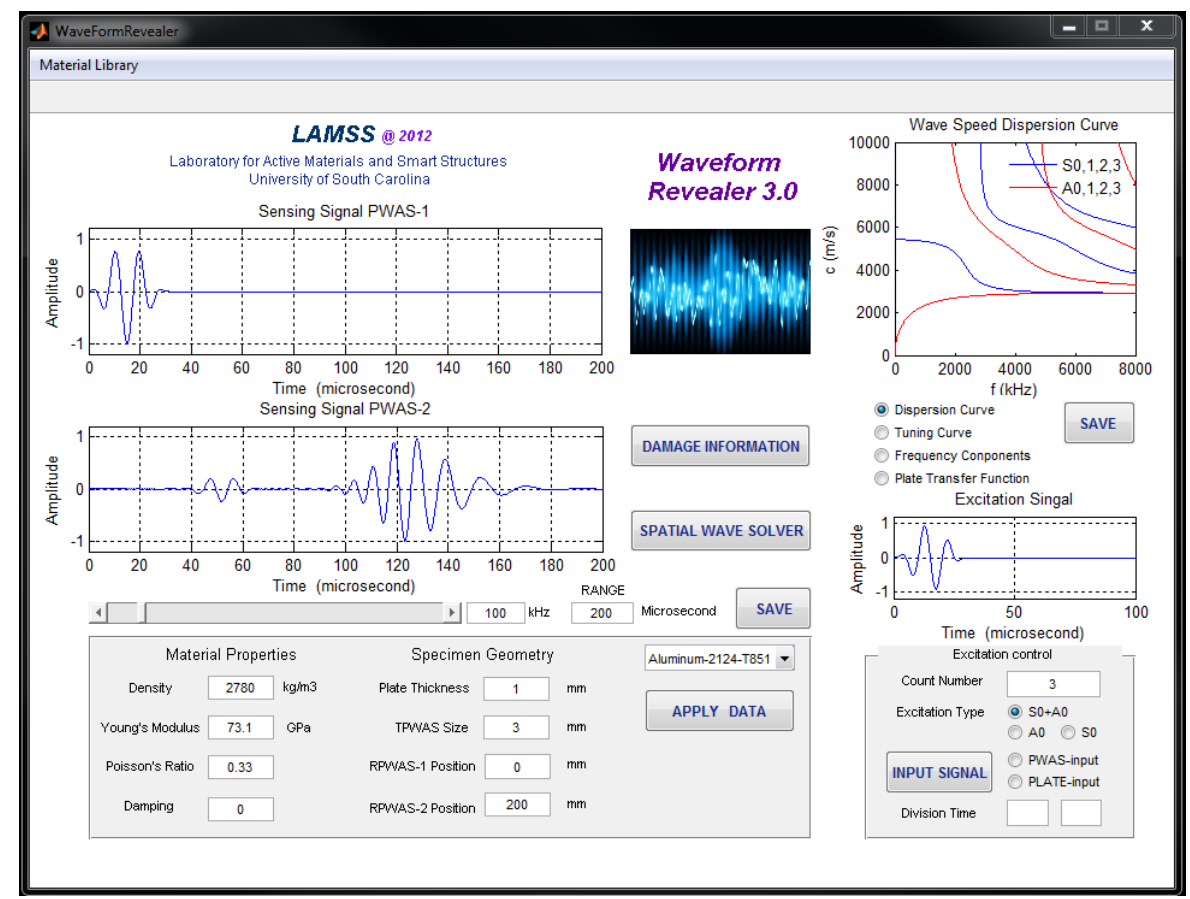

Figure 2: Program “WAVE FORM REVEALER 3” - LAMSS ref. [7]

"The Wave Form Reveller 3.0 (see Fig. 2) is a predictive tool to simulate multimode guided waves interaction with damage. This software allows users to obtain the theoretical solution for dispersion curve, tuning curve, frequency components for $\mathrm{SO}$ and $\mathrm{AO}$ wave modes, and the plate transfer function. It can calculate the analytical waveforms under arbitrary engineering situations. Arbitrary, hereby, means different kinds of materials, various setup geometries linear interaction with damage, and any kind of excitation signal desired by the users. WFR (WAVE FORM REVEALER) is also capable of obtaining a solution of time-spatial guided waves propagation, which allows users to see how guided waves propagate in the plates." ref. [7] Within the presented work, LAMSS was used to model behaviour on the panel from chapter 1.2. It allowed for rapid changes in selected parameters (including failure models) and comparison with the FE model created using MSC.DYTRAN. Therefore, LAMSS proved to be a very valuable tool for less complex panels and sensor sets - it helped to verify FE models for simple conditions. However, within the presented activities, authors reached the potential of LAMSS (in terms of complexity of simulated tasks) and moved towards more complex tasks modelled using FE models (complex structures made of composite materials with the number of sensors and complex shapes).

\subsection{FE Analysis Inputs - Excitation and Configuration of Excitation in FEM}

The first set of FE models with UGW signals was done for the configuration described in chapter 1.2. Selected excitation signals were 3 sinusoids weighted by the Gaussian window. Amplitudes were created on upper surface of the actuator (see. Fig.5 - surface 2). Instead of amplitude magnitude, velocity of movement of upper actuator surface was modelled. Defined velocity was perpendicular to the actuator surface (in Z-axis direction). Magnitude of velocity varied to create abovementioned 3 sinusoids weighted by Gaussian window (see Fig. 3 - black line). Velocity was later used for FE model of actuator excitation during FE simulations. 


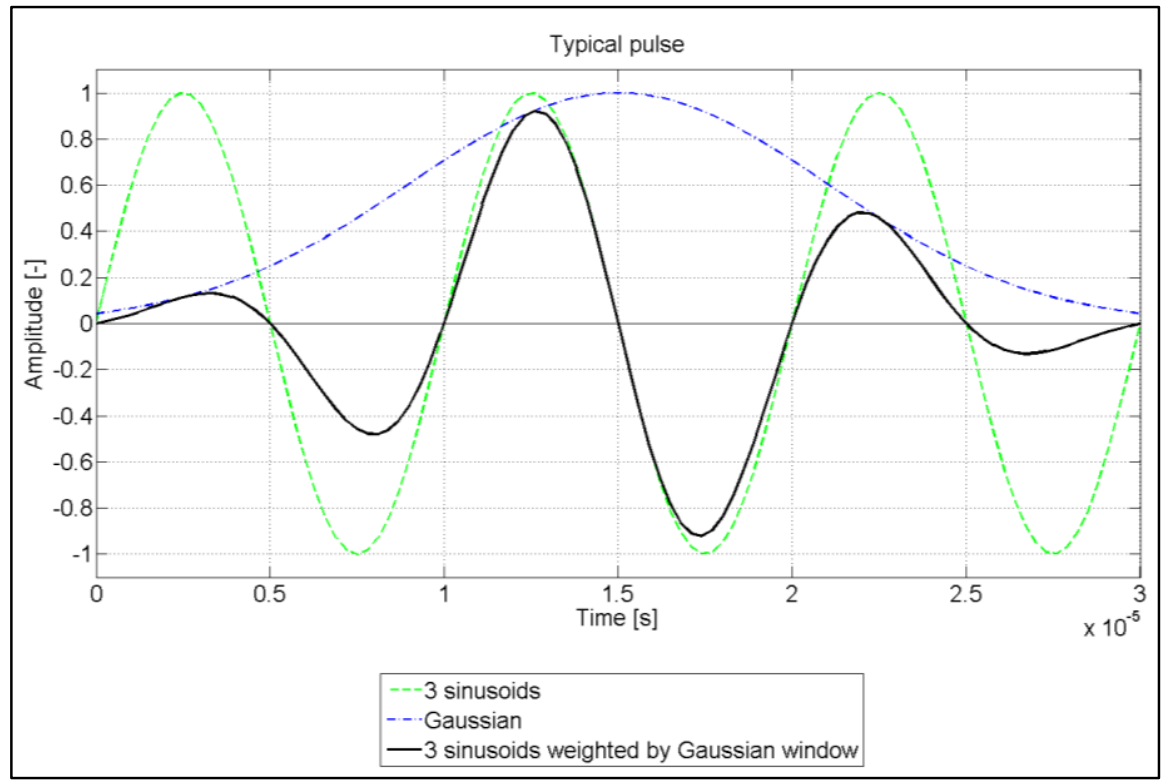

Figure 3: 3 sinusoids weighted by Gaussian window

\subsubsection{Configuration A of actuator and sensor}

Configuration $A$ includes only the panel without sensors. Within FEM, the panel is modelled using 2D QUAD4 elements (2D quadrangle element). Excitation is defined as velocity perpendicular to panel surface (in Z-axis direction). Excitation is applied directly on the panel in the area of the actuator, as well as the sensor signal which is sensed directly from the panel, see Fig. 4.

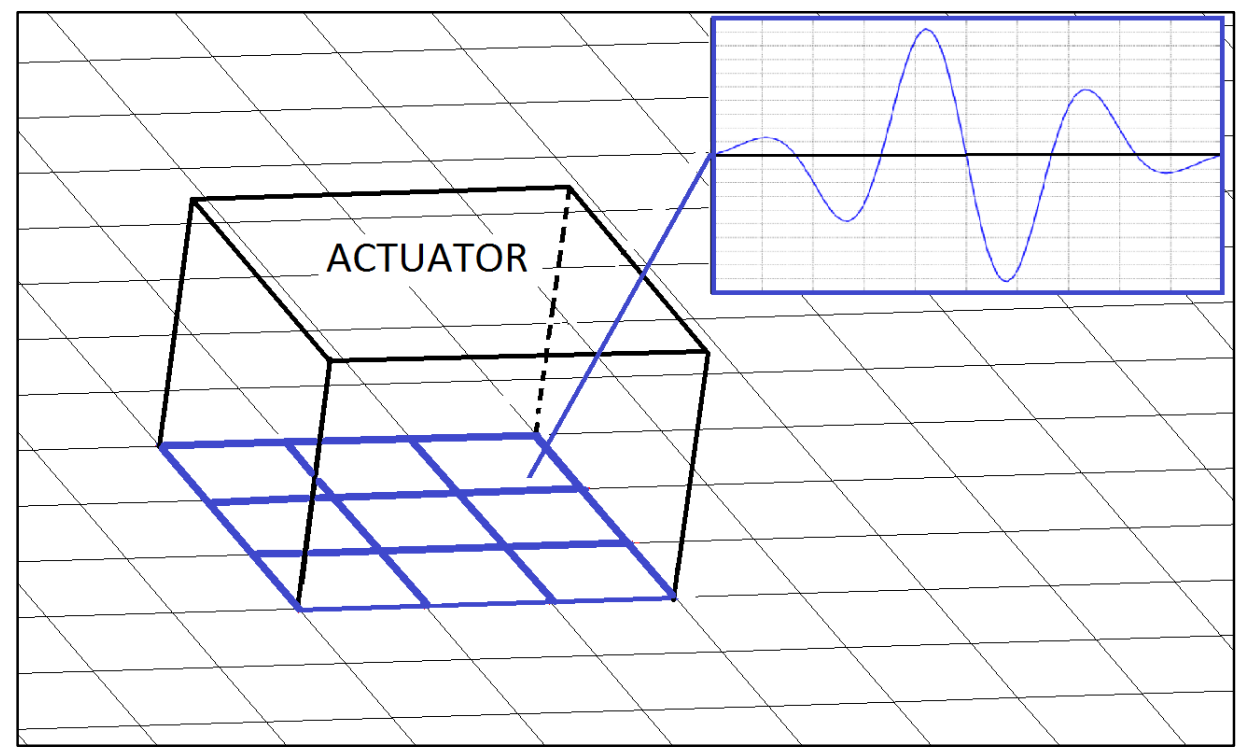

Figure 4: Configuration A of Actuator and sensor

\subsubsection{Configuration B of actuator and sensor}

Configuration B includes the panel and sensors. Within FEM, the panel is modelled using 2D QUAD4 elements (2D quadrangle elements), and sensors are modelled using 3D elements HEX8 (3D element with 6 faces). Excitation is defined as velocity perpendicular to panel surface (in Z-axis direction). Excitation is applied on the upper surface of the Actuator surface2, see Fig. 5. The sensor is composed of $3 \mathrm{D}$ elements attached to both sides of the panel. This configuration allows identification of symmetric (see Fig. 5) and antisymmetric waves (see Fig. 5). 


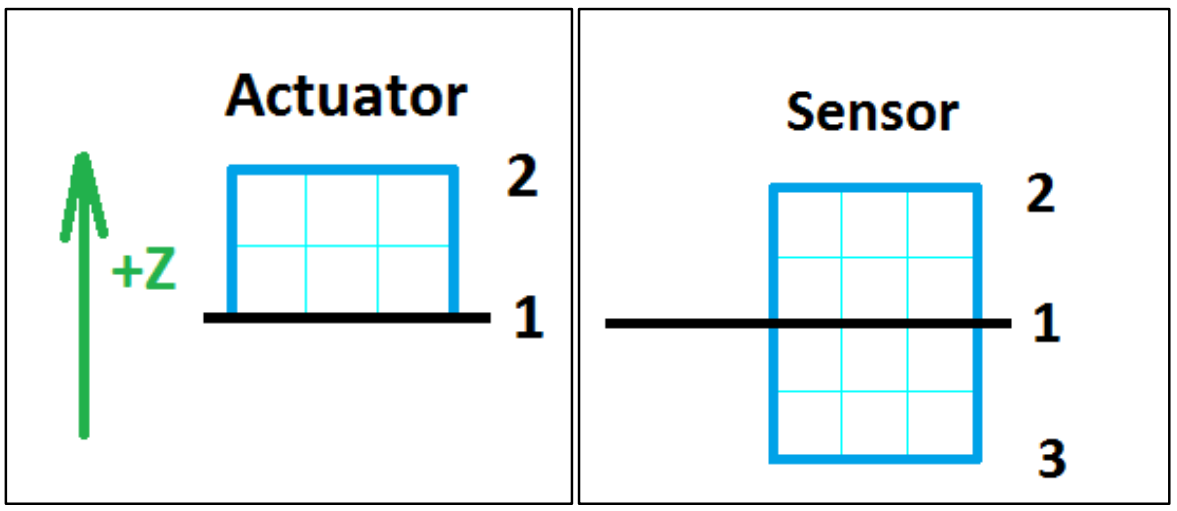

Figure 5: Configuration B of Actuator and Sensor

\subsection{FEM Results - Simple example}

FE simulations result in a record of nodes displacement in time (at Actuator and Sensor). The record can be i.e. displacement-time dependency, or velocity-time dependency. If velocity-time dependency is recorded, it is then transformed (using integration) to displacement-time dependency.

Sensor 1 - signal from sensors surface1 (middle side between the sensor and panel) see Fig. 5

Sensor 2 - signal from sensor surface2 (the upper side of the upper sensor) see Fig. 5

Sensor 3 - signal from sensor surface3 (the lower side of the lower sensor) see Fig. 5

Signal A - difference between the amplitude at surface 1 and 2 , Signal $A(t)=$ Sensor $2(t)$ - Sensor $1(t)$

Signal B - difference between the amplitude at surface1 and 3, Signal $B(t)=$ Sensor $3(t)$ - Sensor $1(t)$

Displacement-time dependency is normalized to amplitude 1. This is done before multiplication using inversed max. amplitude value during the whole simulation:

- For antisymmetric wave

$$
\text { Amplitude } n_{\text {tantis }}=\text { Amplitude }_{t}\left(\frac{1}{\text { MAX (Amplitude })}\right)
$$

- For symmetric wave

$$
\text { Amplitude } n_{\text {tsym }}\left(0 \div T_{\text {lim }}\right)=\text { Amplitude }_{t}\left(0 \div T_{\text {lim }}\right)\left(\frac{1}{\operatorname{MAX}\left(\operatorname{Amplitude}\left(0 \div T_{\text {lim }}\right)\right)}\right)
$$

- Scale

$$
\text { Scale }=\left(\frac{1}{\text { MAX (Amplitude })}\right) \quad \text { or } \quad \text { Scale }=\left(\frac{1}{\text { MAX }(\text { Amplitude }(0 \div \text { Timelim }))}\right)
$$

Where:

Amplitude $n_{\text {tantis }}, n_{\text {tsym }}$ normalized amplitude in time $t$ (max amplitude equal to 1) for antisymmetric wave and symmetric wave

Amplitude ${ }_{t} \quad$ amplitude in time $t$

Max(Amplitude) max. amplitude value during whole simulation

$(0 \div$ Time limit $) \quad$ time interval 0 to Time limit $\left(T_{\text {lim }}\right)$ for indication symmetric wave 

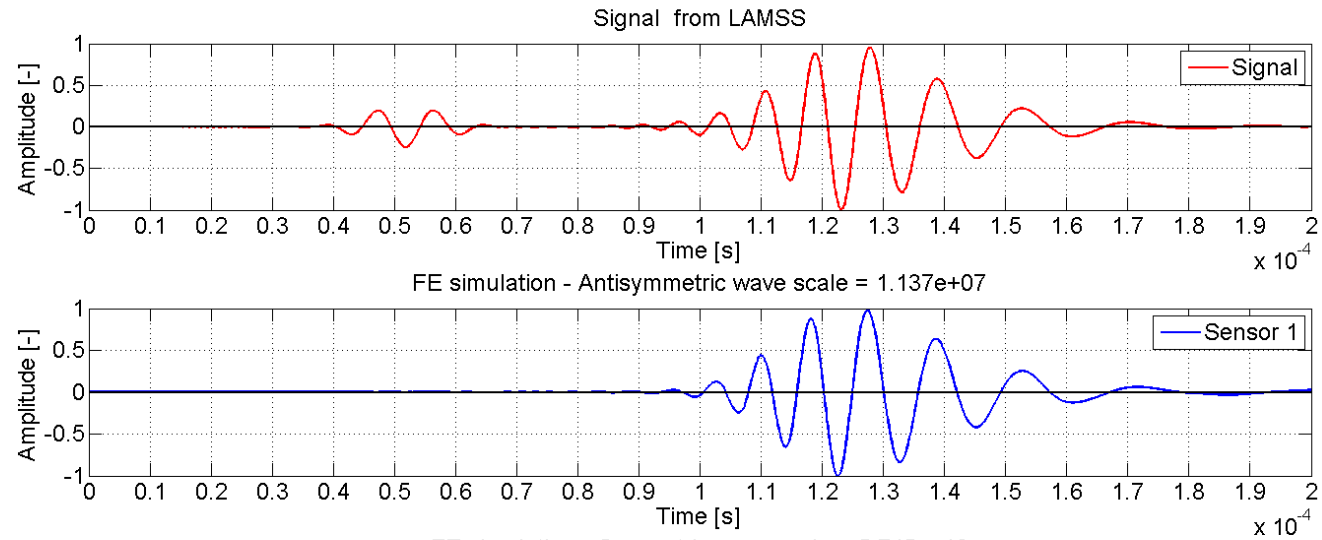

FE simulation - Symmetric wave scale $=5.745 \mathrm{e}+10$

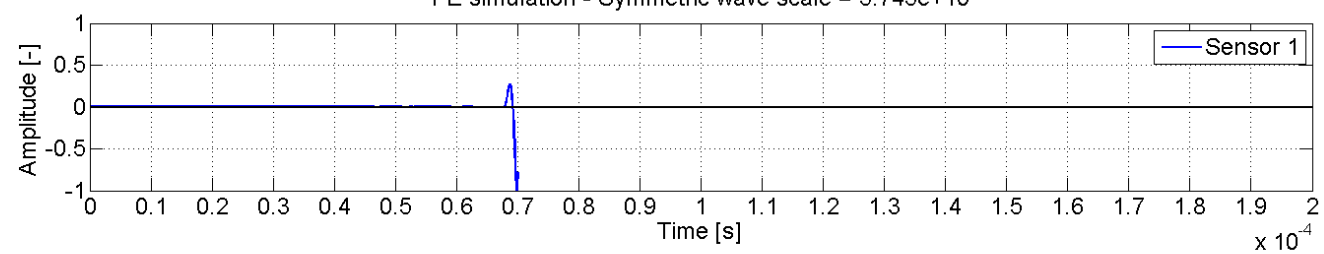

Figure 6: Result of FEM analysis for configuration A, and comparison with LAMSS

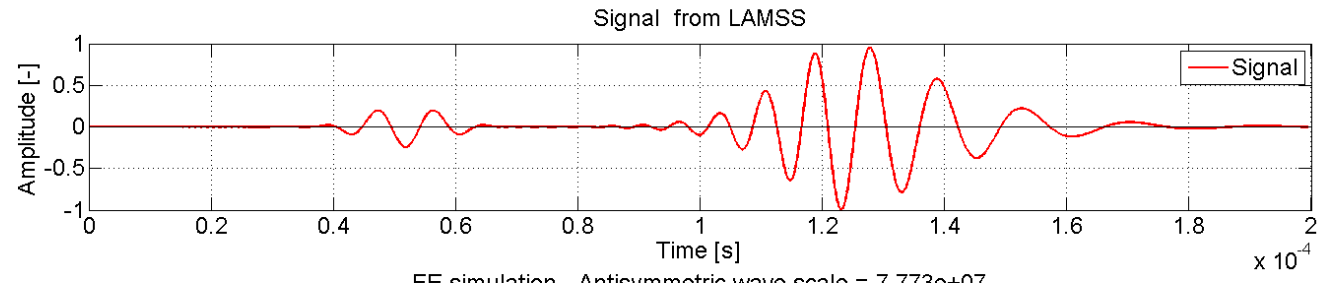

FE simulation - Antisymmetric wave scale $=7.773 \mathrm{e}+07$

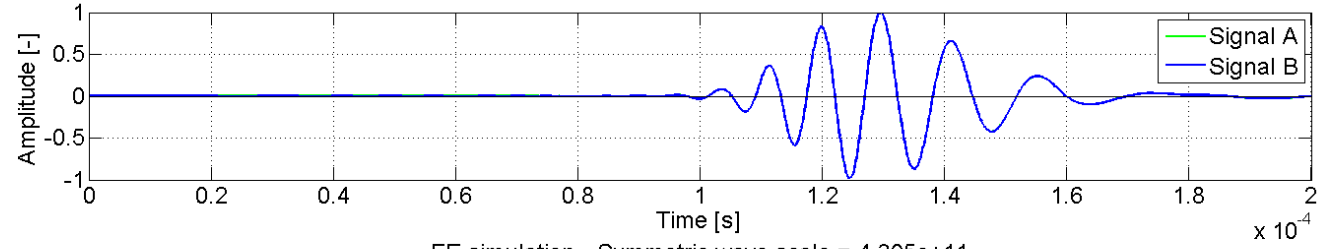

FE simulation - Symmetric wave scale $=4.305 e+11$

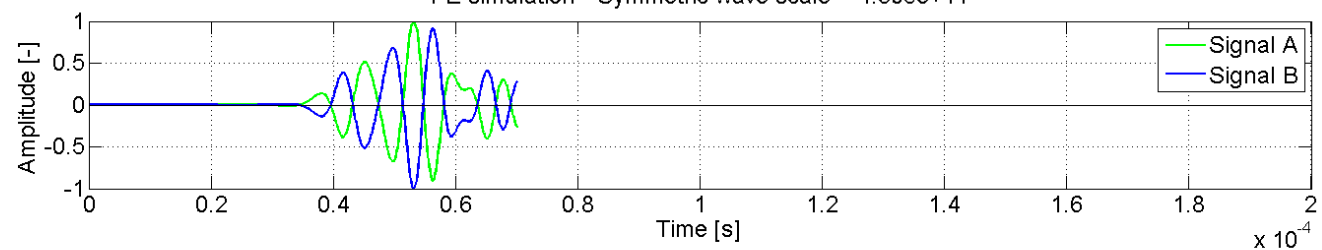

Figure 7: Result of FEM analysis for configuration B, and comparison with LAMSS 


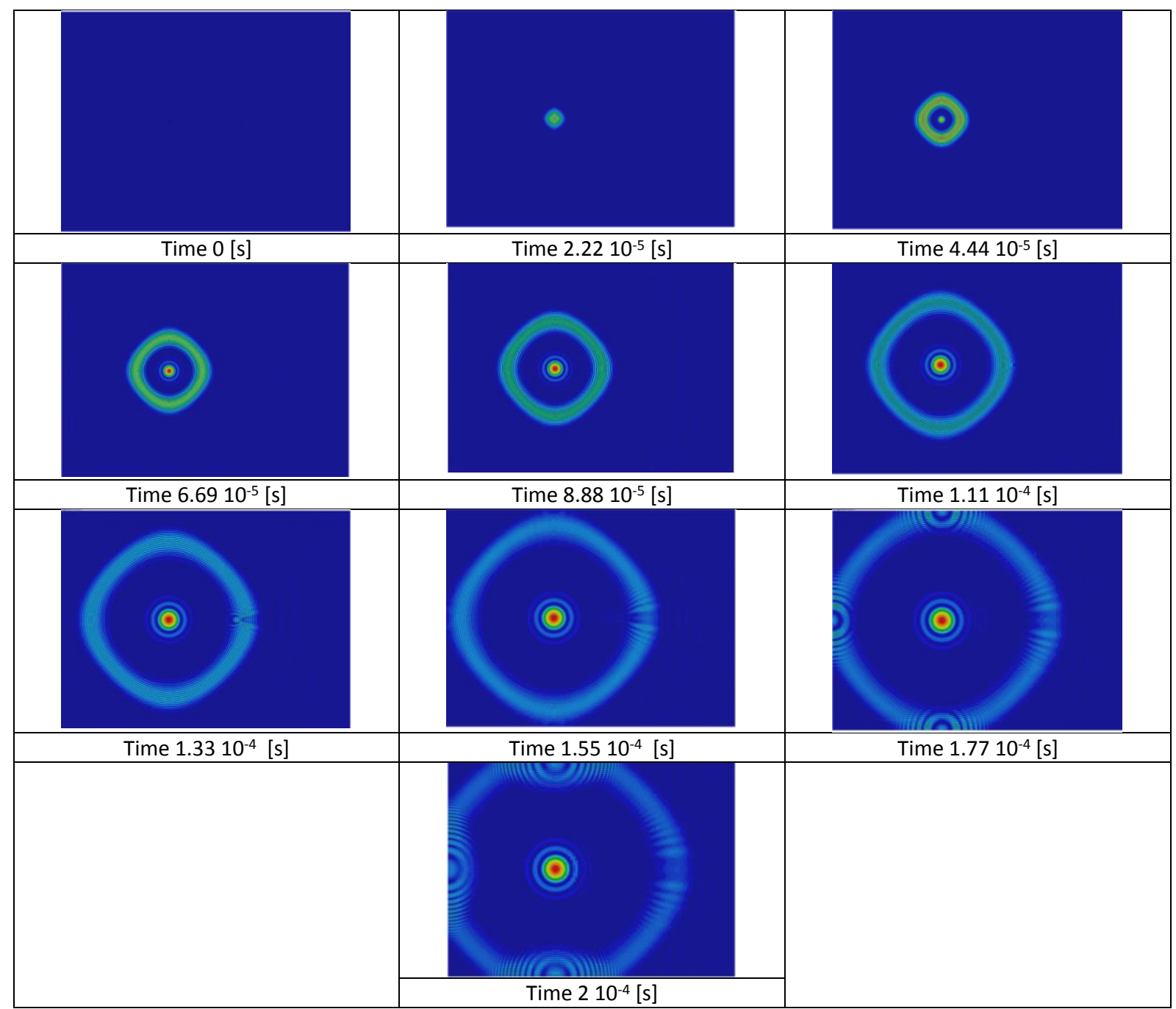

Table 3: Map of displacements for wave propagation (Time 0 to $210^{-4}$ [s])

\subsection{Summary}

Configuration A (only 2D panel) has good agreement between FE simulation and LAMSS solution in the area of antisymmetric waves. Symmetric waves are not identifiable for this configuration see Fig.6. Only waves perpendicular to the panel surface (in z-axis directory) are sensed. The shape and propagation of waves in the panel is shown on the figures in Tab.3.

Configuration B (2D panel and 3D sensor) has very good agreement between FEM simulation and LAMSS solution in the area of antisymmetric waves and the symmetric waves are also identifiable for this configuration with good agreement see Fig.7. This is a valid FEM system for excitation frequency $100 \mathrm{kHz}$.

Performed analyses and simulations clearly show, that FEM software system in configuration 2D panel/3D sensor (Configuration B) is able to simulate UGW propagation with very good agreement (compared to each other, and to "etalon" solution). These FEM software packages (MSC.Patran/MSC.Dytran), combined with excitation configurations B will be further used as basic configurations for UGW propagation simulation in all-composite panels. 


\section{ADVANCED FE MODEL - DETECTION AREAS FOR UGW SIGNALS USING FE MODELLING}

Detection areas are a key element for the future optimization of the number and placement of health monitoring sensors. For practically applicable procedure, it is necessary to link the sensor detection areas to different types of damage (structural failures). Sensor detection areas are (for our purpose) areas on the structure, where the probability of damage detection is on a certain satisfactory level. Detection areas depend not only on the required level (probability of detection level), but also on damage type, distance from sensor pair and material layers. The following "structural damage (failure) types" were selected for FE simulations:

- $\quad$ hole - complete damage of the panel (hole through the panel thickness),

- delamination - change of material characteristics in internal layers in the damaged area,

Considered structural damage types are simplified for FE simulations and applied on a defined composite panel separately. The described damage types are typical for composite panels.

During simulations, sensor signals (i.e. changes in displacement velocity) are recorded in selected nodes. Later, displacement on the sensor (sensor deformation) is evaluated. This signal is recorded on the panel without damage and on the panel with defined damage. Signals from undamaged and damaged panels are compared, and from their difference and multiplication, structural damage is evaluated.

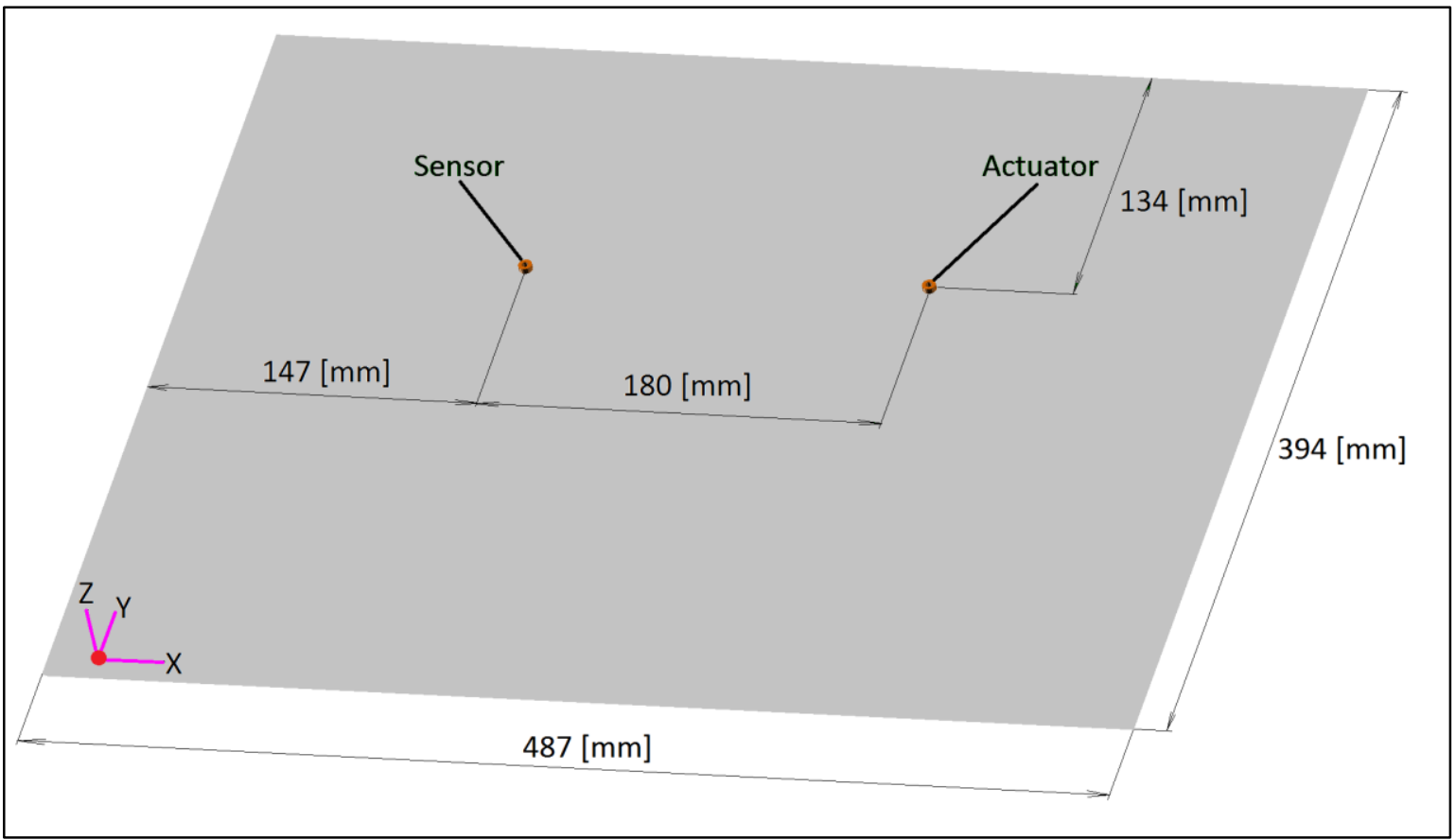

Figure 8: Geometry of FEM panel

\subsection{Panel and material}

The basic specimen for FE simulations of detection areas is the composite panel with dimensions of 487x394 [mm]. Two layering options were used (unidirectional and orthotropic), see Fig. 8. A total of four sensors were placed on the panel: Sensor No.1 was actuator, the remaining sensors were only sensing actuated signal. Between the actuator and the sensor different damage types were placed (with different damage locations). Differences on sensor signals were tracked. Main focus was given to sensor, resp. to the pair of Actuator - Sensors. 
The first analysed laminate was a unidirectional, 12-plies laminate $\left[0^{\circ}\right] 12$ - PANEL 0 . The second laminate had 18 plies, an orthotropic lay-up of $\left[-45^{\circ} / 0^{\circ} / 45^{\circ} / 45^{\circ} / 0^{\circ} /-45^{\circ} /-45^{\circ} / 0^{\circ} / 45^{\circ}\right]$ s - PANEL 45 .

For both laminates, carbon fibre material HITEX 33 6K/E7K8 was used. Material was selected from material database $\mathrm{CMH}$-17. Material characteristics used for FE simulations are shown in [12]. Material characteristics used for FEM simulations are shown in Tab. 4.

\begin{tabular}{|l|c|c|}
\hline Young's modulus 1 & E1 & $125485[\mathrm{MPa}]$ \\
\hline Young's modulus 2 & E2 & $8618[\mathrm{MPa}]$ \\
\hline Shear modulus 12 & $\mathrm{G} 12$ & $5400[\mathrm{MPa}]$ \\
\hline Shear modulus 31 & $\mathrm{G} 31$ & $5400[\mathrm{MPa}]$ \\
\hline Shear modulus 23 & $\mathrm{G} 23$ & $5400[\mathrm{MPa}]$ \\
\hline Poisson's ratio & $\mu$ & 0.31 \\
\hline Mass density & $\rho$ & $1580\left[\mathrm{~kg} / \mathrm{m}^{3}\right]$ \\
\hline Thickness & $\mathrm{t}$ & $0.145[\mathrm{~mm}]$ \\
\hline
\end{tabular}

Table 4 : Material characteristic for FEM simulation

\section{Set-up of the numerical analysis}

The MSC.Dytran system was used to calculate propagation of UGW with the following settings:

End time $=510^{-4}[\mathrm{~s}]$, initial time step - INISTEP, $0.310^{-7}[\mathrm{~s}]$, maximal time step - MAXSTEP, $10^{-7}[\mathrm{~s}]$, and minimal time step - MINSTEP, $10^{-8}[\mathrm{~s}]$.

\subsection{Damage types}

\subsubsection{Hole}

This type of damage (failure) means complete panel damage after impact of the object with a sharp edge. It supposes damage through the whole thickness of the panel. In this case, no delamination is expected around the "Hole". The diameter of the hole was $3[\mathrm{~mm}]$ see Fig. 8.

\subsubsection{Delamination}

This type of damage (failure) represents delamination in panel layer, created during impact of foreign object (where complete damage - "hole" - does not occur). Delamination was modelled as change in layer parameters (see Fig. 9), material properties in the area of delamination were modified in accordance with Table 4. The delamination shape was always circular and two diameters were modelled, 6 and 10 [mm].

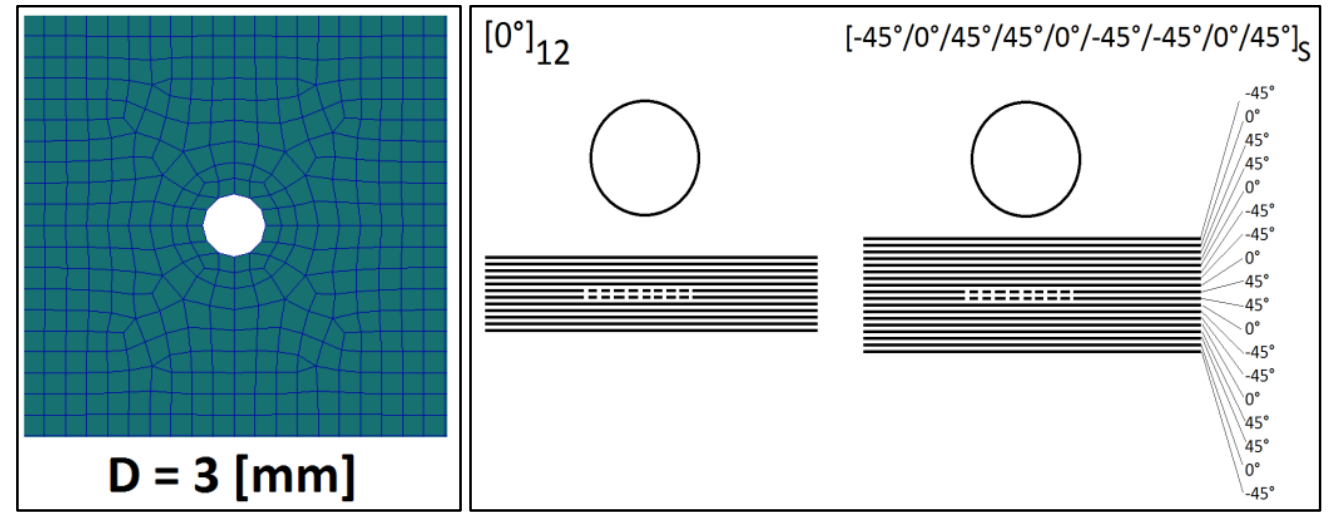

Figure 9: Damage type "Hole" FE model (right) and Symmetrical delamination - position (left) 


\subsection{Evaluation procedure}

To obtain UGW sensor detection area from FE simulations, following mechanism was applied:

1. Signal received on the panel without damage (see Fig. 10 and Fig. 11) is "reference signal" necessary for finding cracks:

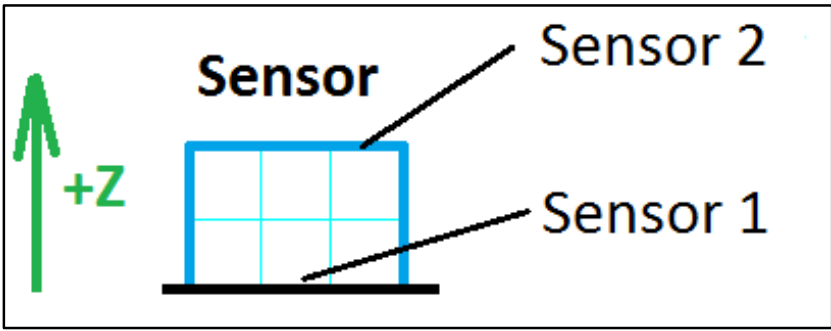

Figure 10: Position of signal for evaluation procedure

Sensor $1 \mathrm{z}-$ signal from sensor surface 1

Sensor $2 z$ - signal from sensor surfece 2

"Reference signal" for finding damage: Signal A without damage = Sensor 2 z - Sensor 1 z

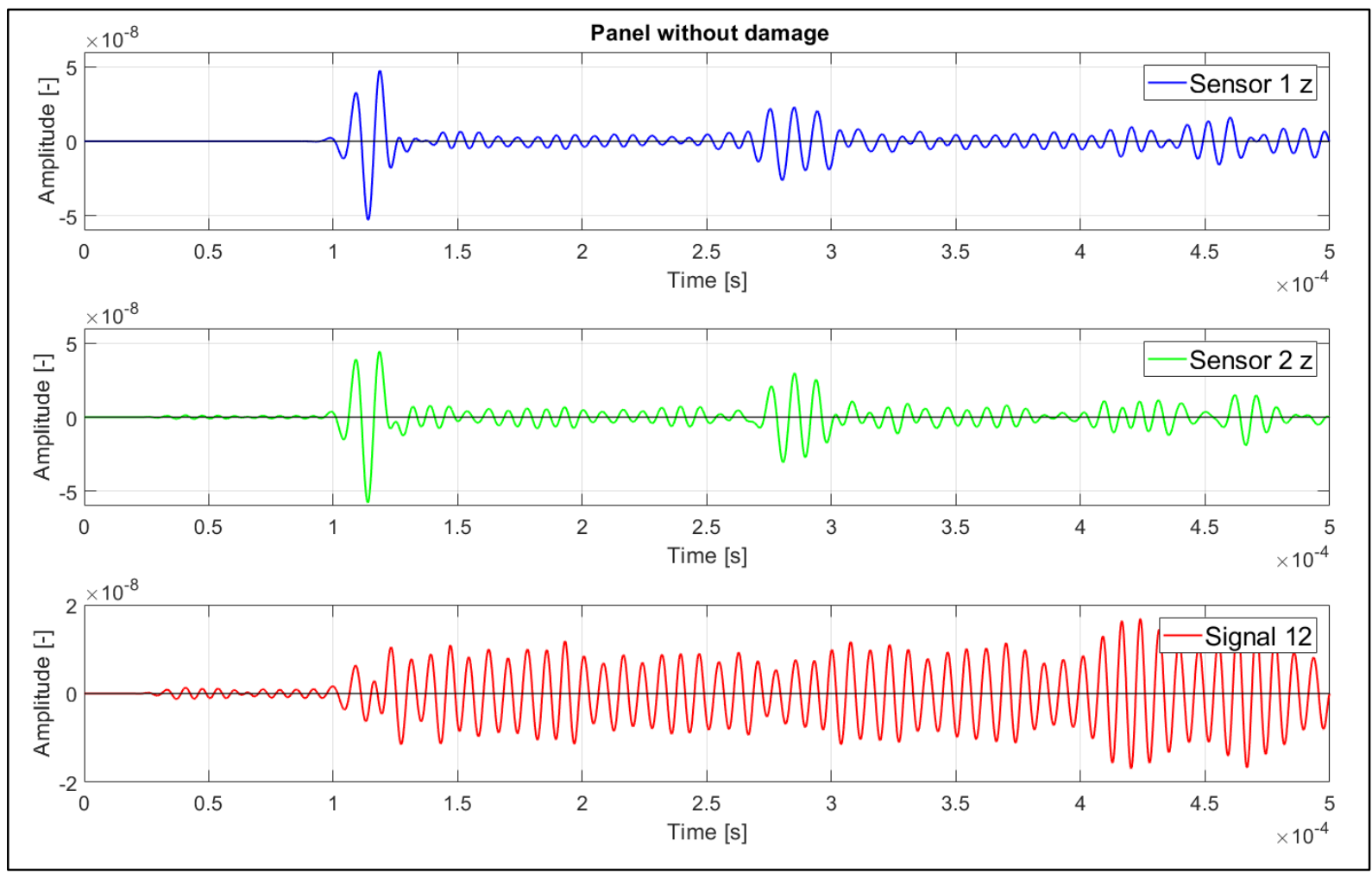

Figure 11: Signal for sensor 4 - panel without damage 


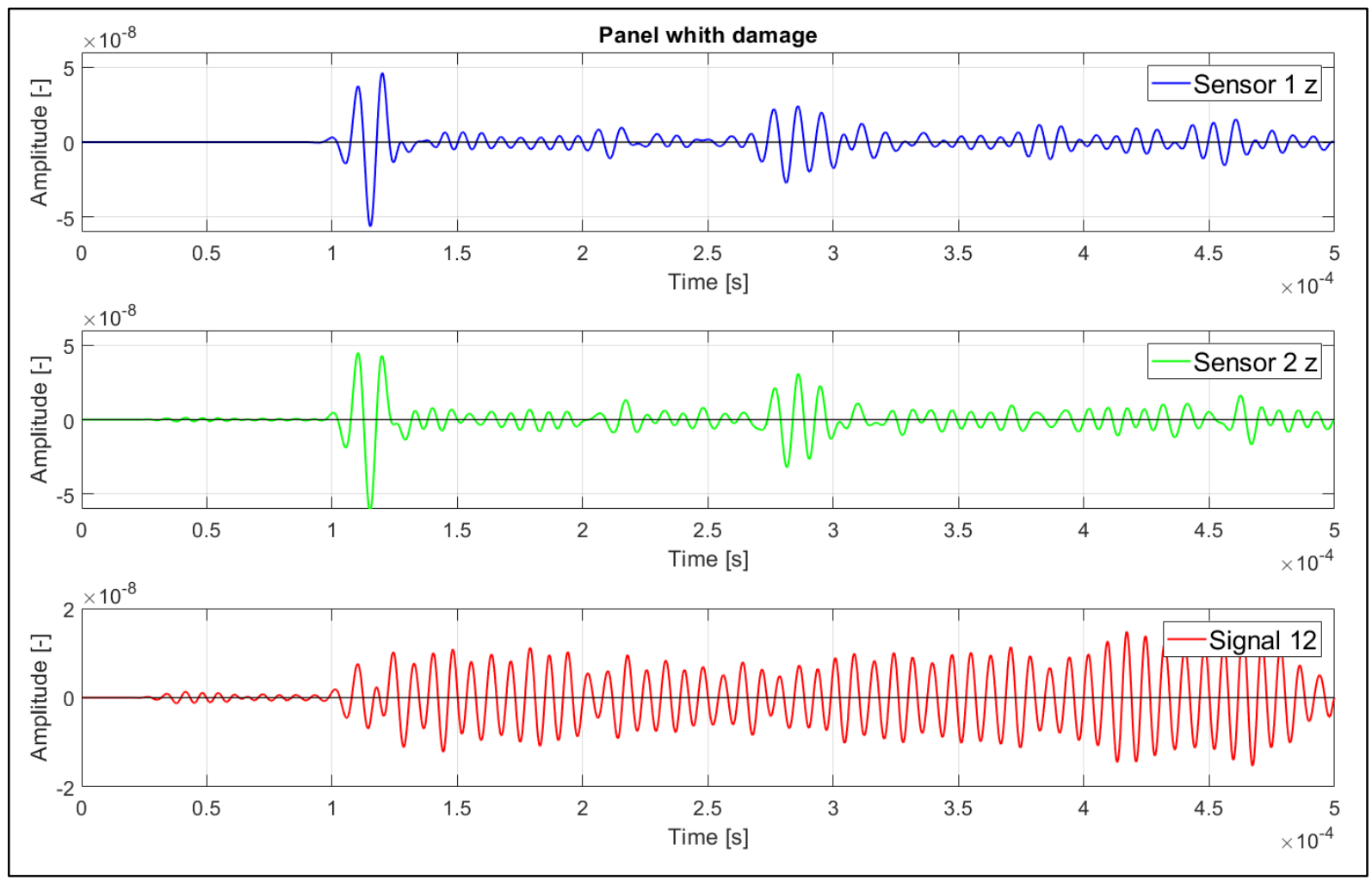

Figure 12 signal for sensor 4 - panel with damage (Hole)

2. Signal received from the panel with damage (Fig. 12):

Sensor $1 \mathrm{z}$ - signal from sensor surface 1

Sensor $2 \mathrm{z}-$ signal from sensor surface 2

\section{Signal $\mathrm{A}$ with damage $=$ Sensor $2 \mathrm{z}-$ Sensor $1 \mathrm{z}$}

3. Amplitude signal was filtered using two channel frequency classes (CFC) filter ref. [13].

4. Determination of the difference between the signals from the panel without damage and the panel with damage:

\section{Delta Signal $=$ Signal A without damage - Signal A with damage}

5. Scaling of the Delta Signal on the unit amplitude:

No time limit was predefined - the time was determined based on waves propagation in the panel so that signal is not influenced by signals reflected from panel edges and other sensors (see Fig. 13). Further, "scale" parameter was defined so that max. amplitude in time range 0 "Limit time" is equal to 1.

$$
\text { Scale }=\frac{1}{M A X(\text { Delta Signal }(0 \div \text { Limit time }))}
$$

"Limit time" defines an interval (0 - "Limit time"), where the "Scale" parameter shows the possibility of damage detection (in a similar way as probability of detection). This time corresponds to the time of signal propagation between the sensor and the actuator with sufficient reserve see Fig. 13. This time should not be too long, otherwise it would include also sensing of reflected waves. Value of "Limit time" used was $t=1.75$ e-4 [s].

In addition, an estimate on damage detection possibility was done as " $1 /$ Scale", the bigger is value " $1 /$ Scale", the bigger is probability of damage detection and vice versa. 


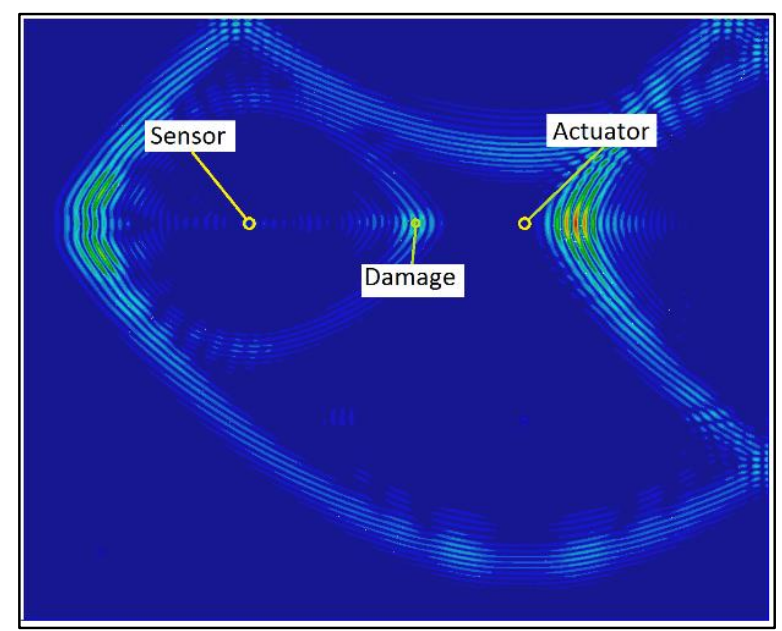

Figure 13: waves at "limit time" $t=1.7510^{-4}[\mathrm{~s}]$, layering Panel_00

\subsection{Results - Detection Areas}

Using the above-described procedure, it was possible to create graphs of detection areas (areas with high probability of detection).

\subsubsection{Hole}

To simulate damage type "Hole", small holes were placed on the panel in the array shown on Fig. 14. Each FE simulation run had only one hole (in one position).

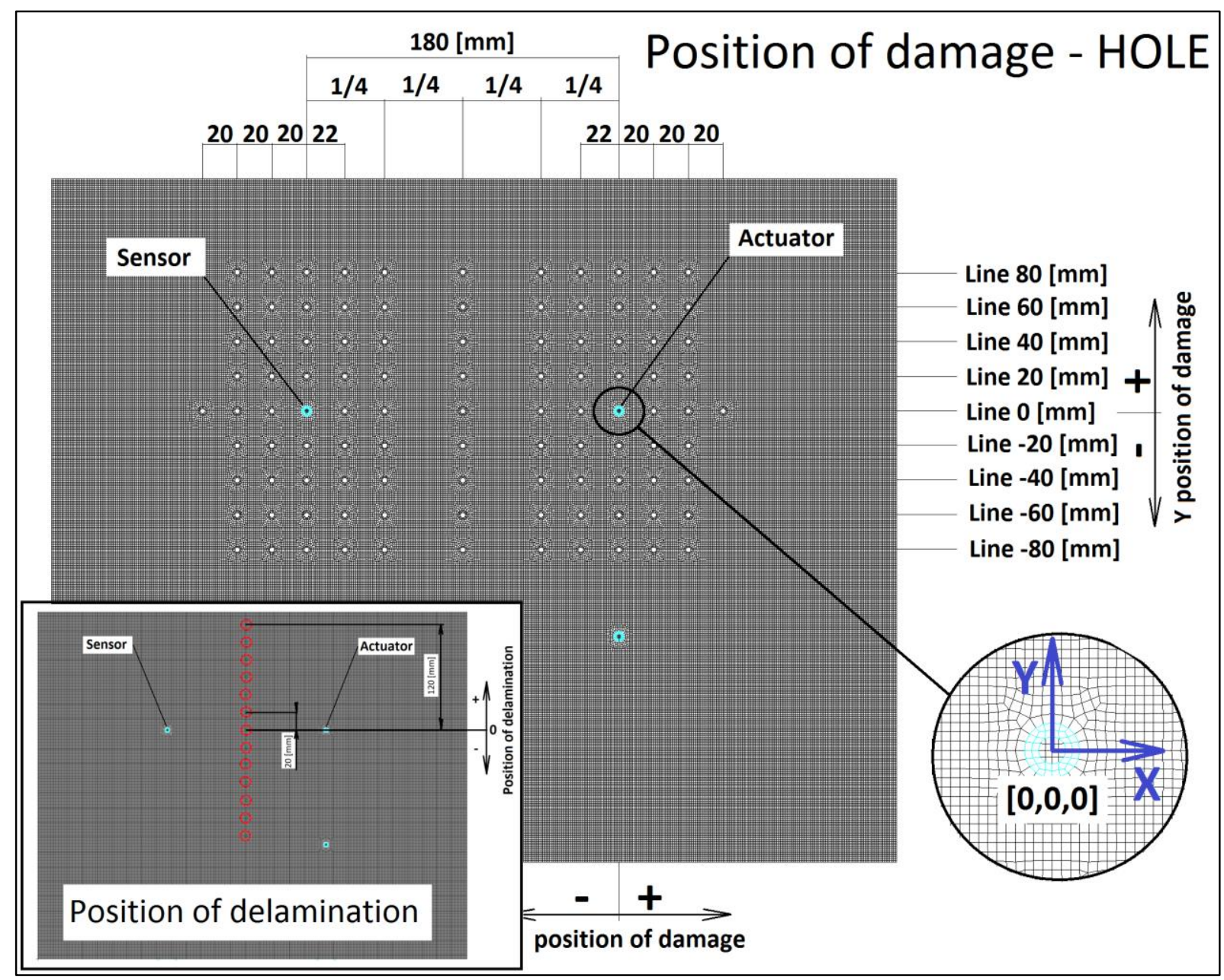

Figure 14: Positions of damage- hole and delamination 


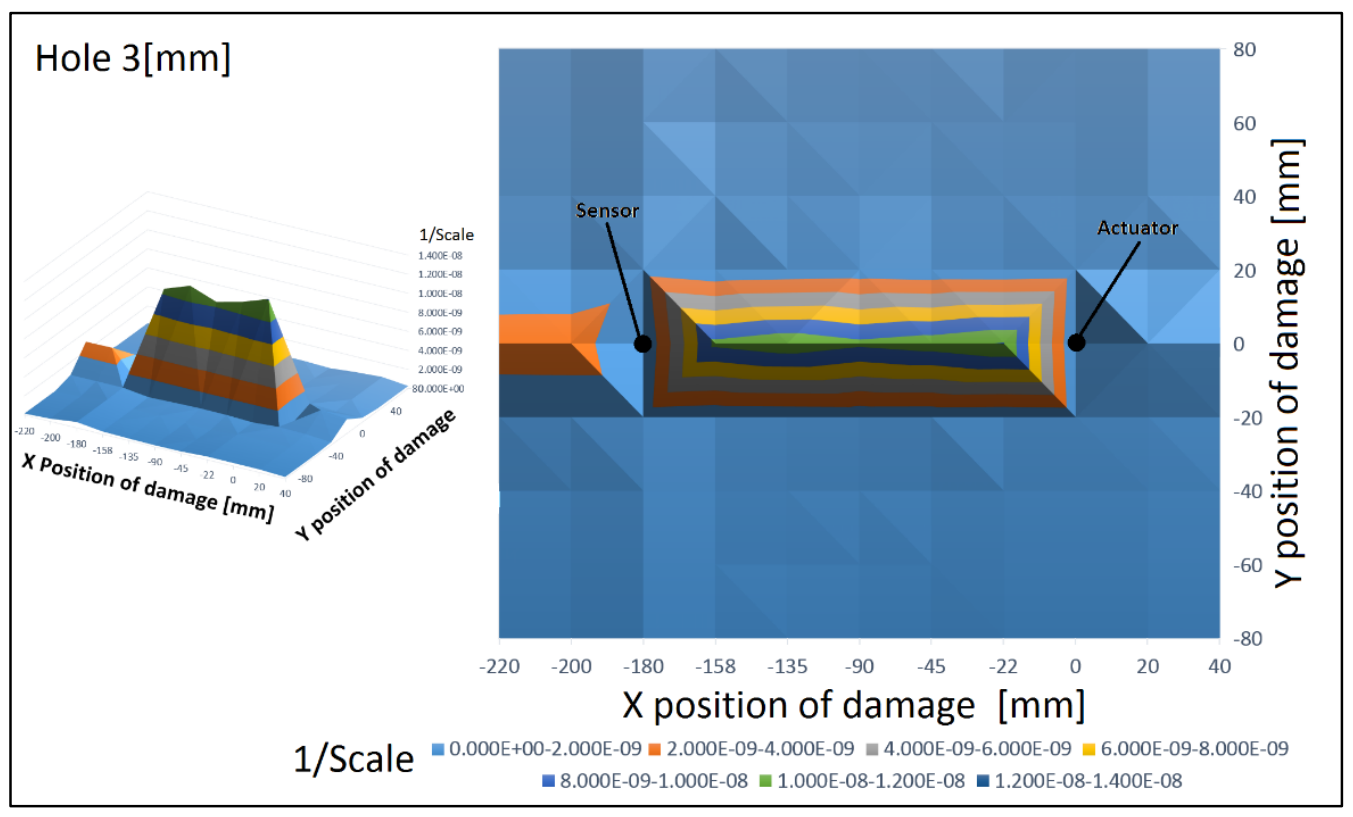

Figure 15: „Likelihood of detection (area of detection)" - Hole (graph of “1/scale” for layering [ $\left.0^{\circ}\right] 12$ )

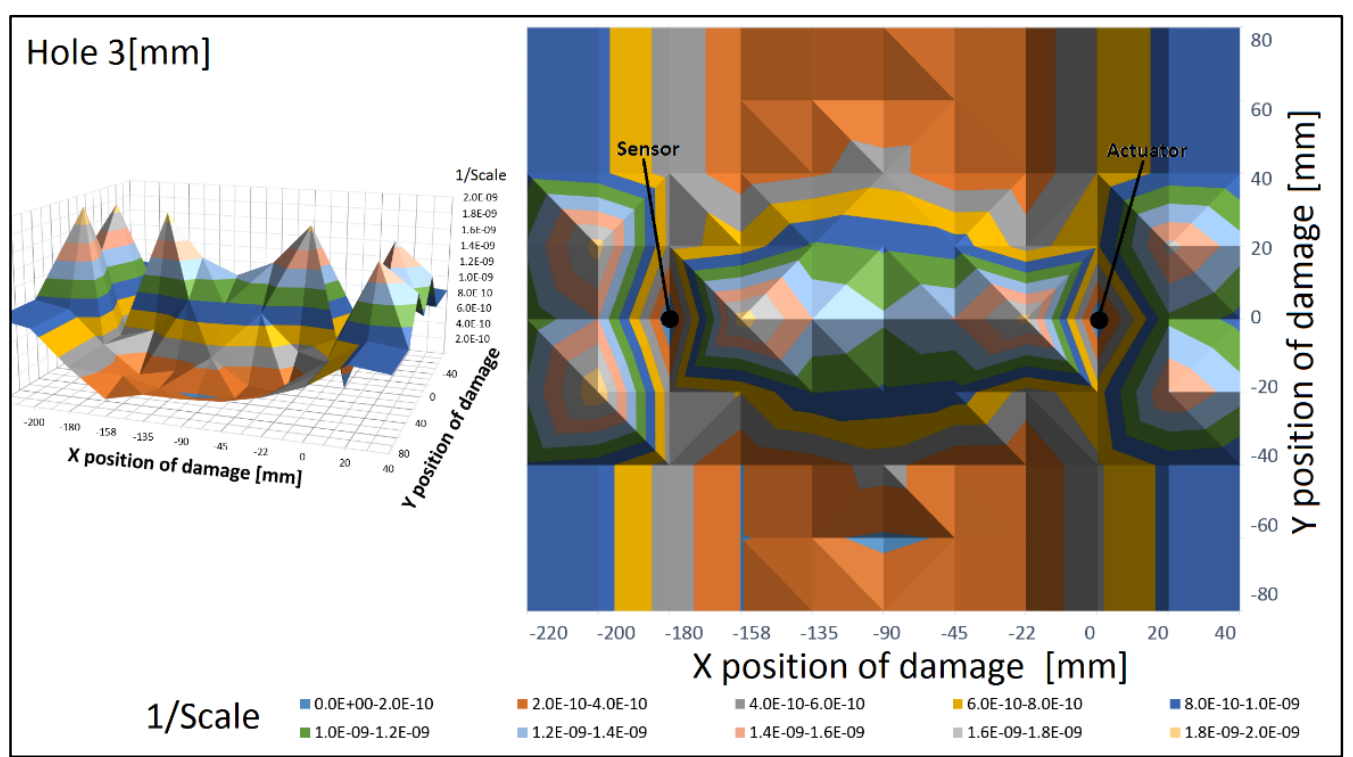

Figure 16: „Likelihood of detection (area of detection)" - Hole (graph of “1/scale” for layering $\left[-45^{\circ} / 0^{\circ} / 45^{\circ} / 45^{\circ} / 0^{\circ} /-45^{\circ} /-45^{\circ} / 0^{\circ} / 45^{\circ}\right]$ s )

\subsubsection{Delamination}

To simulate damage type "Delamination", simulated damages were placed in the line shown on Fig. 14. Each FE simulation run had only one damage (in one position). 


\section{Symmetrical delamination}

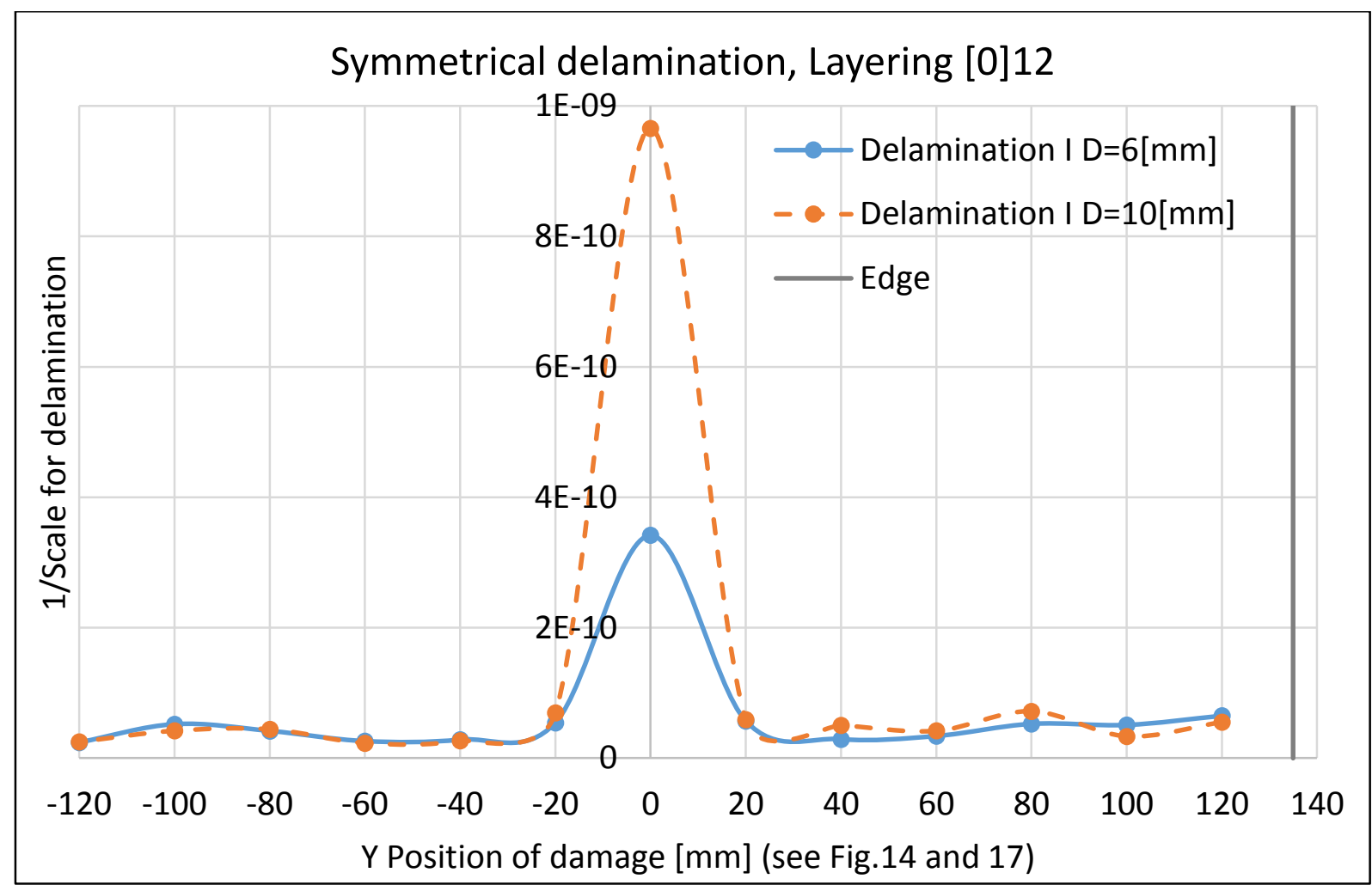

Figure 17: „Likelihood of detection (area of detection)" - Delamination (Graph of “1/scale” for layering [0 $\left.{ }^{\circ}\right] 12$ ), Edge - edge of the panel

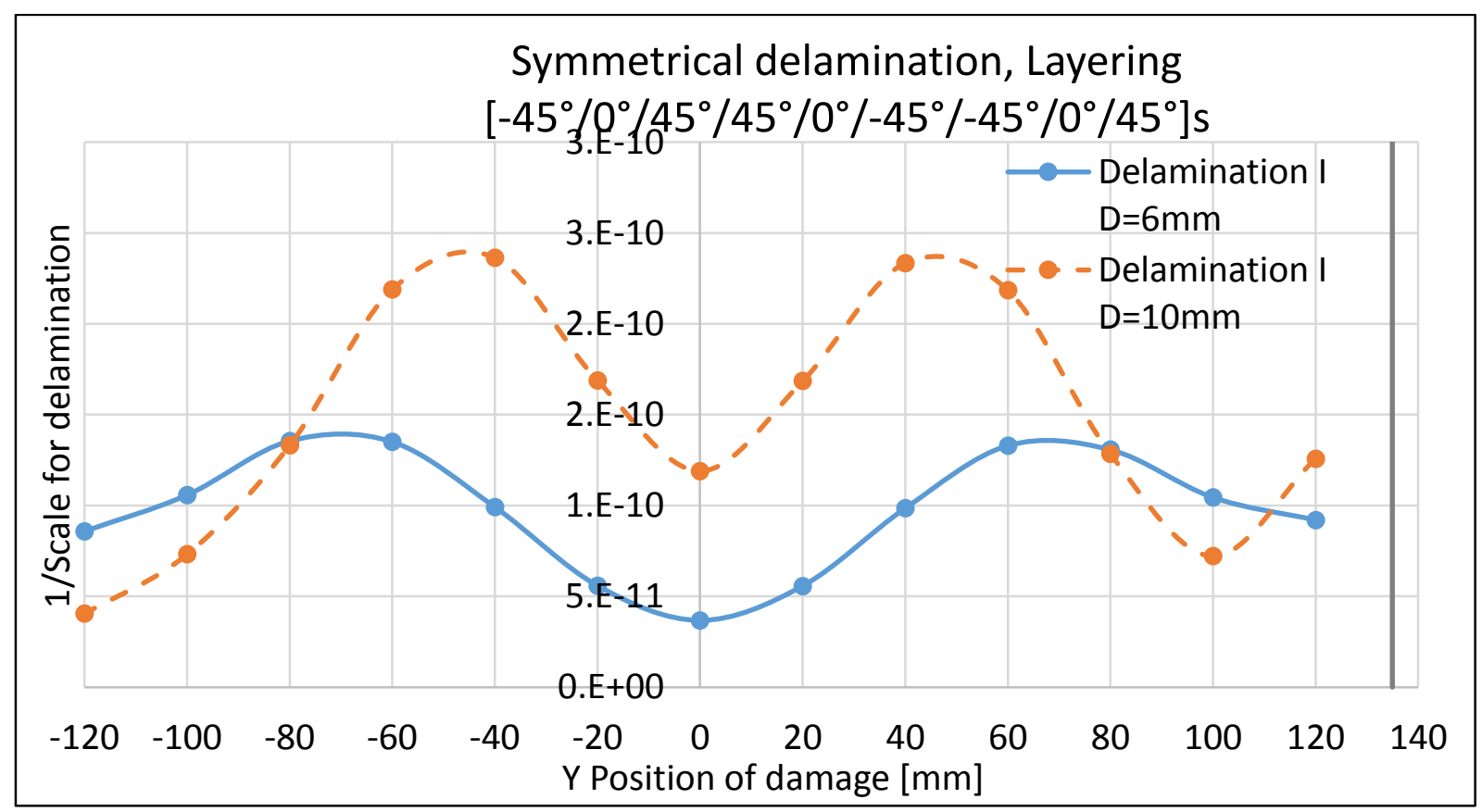

Figure 18: „Likelihood of detection (area of detection)" - Delamination (Graph of “1/scale” for layering $\left[-45^{\circ} / 0^{\circ} / 45^{\circ} / 45^{\circ} / 0^{\circ} /-45^{\circ} /-45^{\circ} / 0^{\circ} / 45^{\circ}\right]$ s)

Comparison of " $1 /$ Scale" values in the cut perpendicular to connecting line of sensors, for hole diameter 3 [mm] and delamination are shown in Fig. 19 and 20. A nearly "ideal" match in the shape of the curve was received for layering option Panel_0, with difference only in magnitude of " $1 /$ Scale" parameter. On the other hand, a significant difference in shape and magnitude can be tracked for layering option Panel_45. This is probably caused by the fact that the hole influences all layers in 
laminate (through whole thickness), however selected delamination is only connected to two middle layers (both with $45^{\circ}$ ). Larger delamination (covering more layers, see Fig. 22) has better match, see Fig. 21.

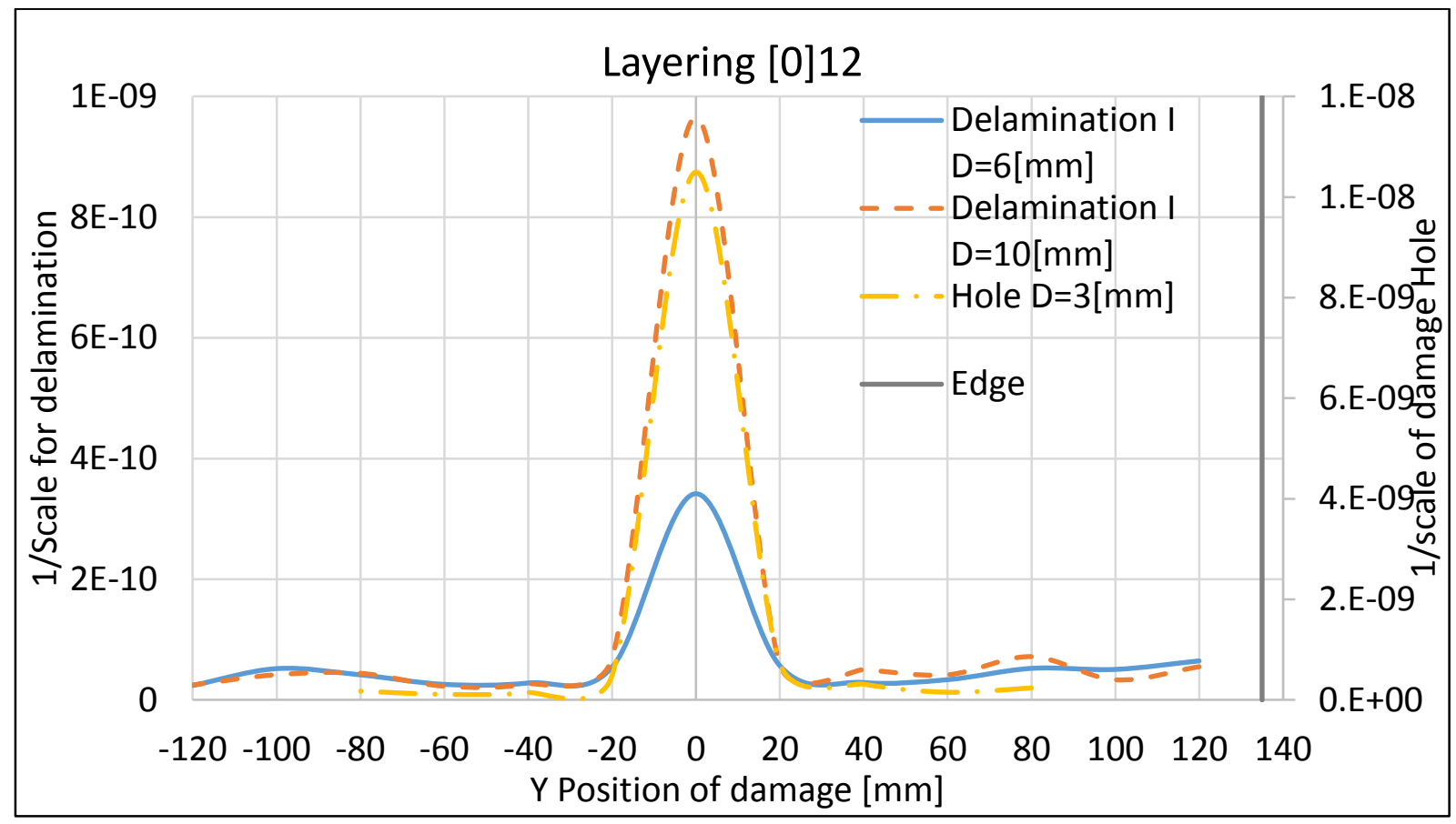

Figure 19: Comparison "1/scale" between hole and delamination, layering Panel_0

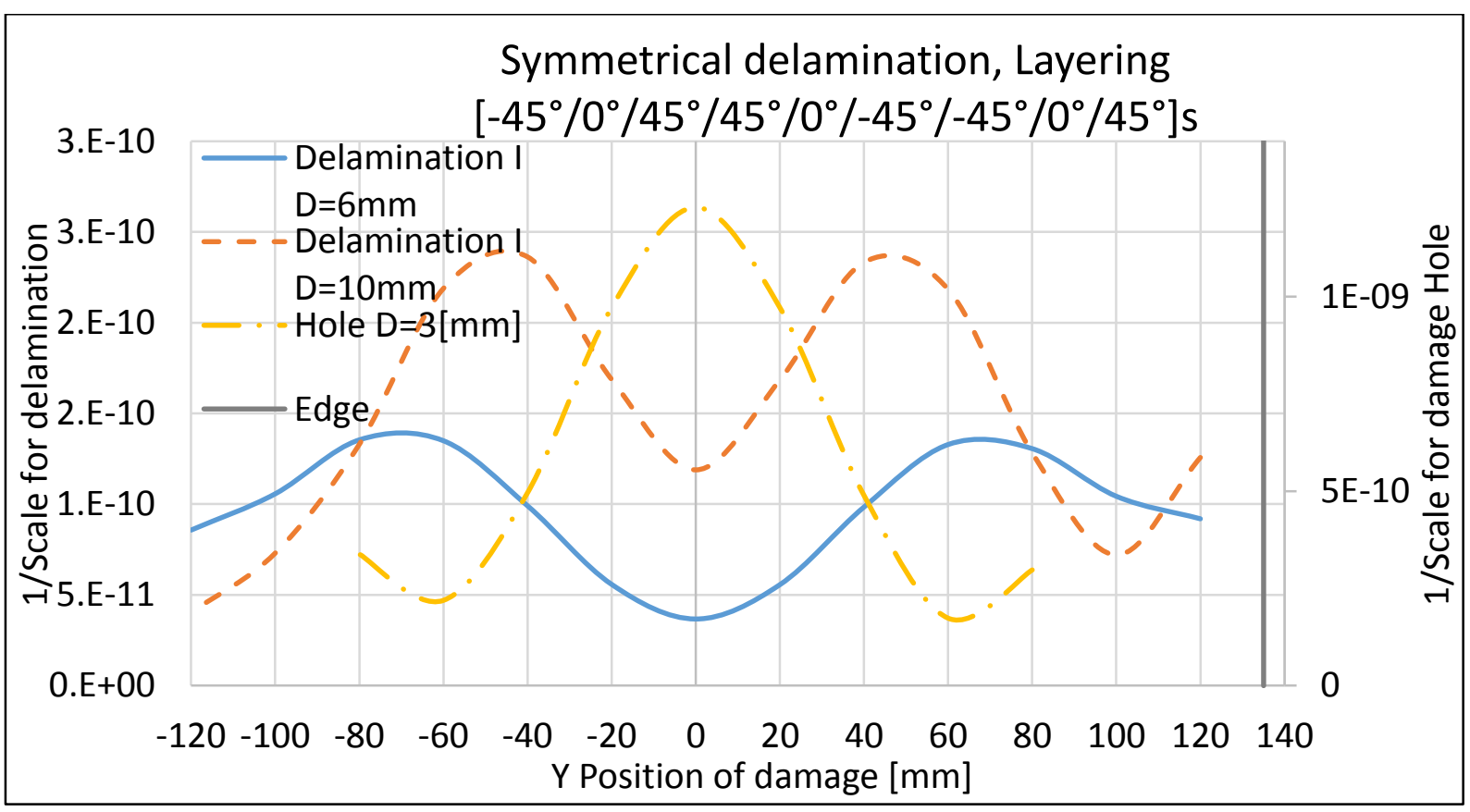

Figure 20: Comparison "1/scale" between hole and delamination, layering Panel_45 


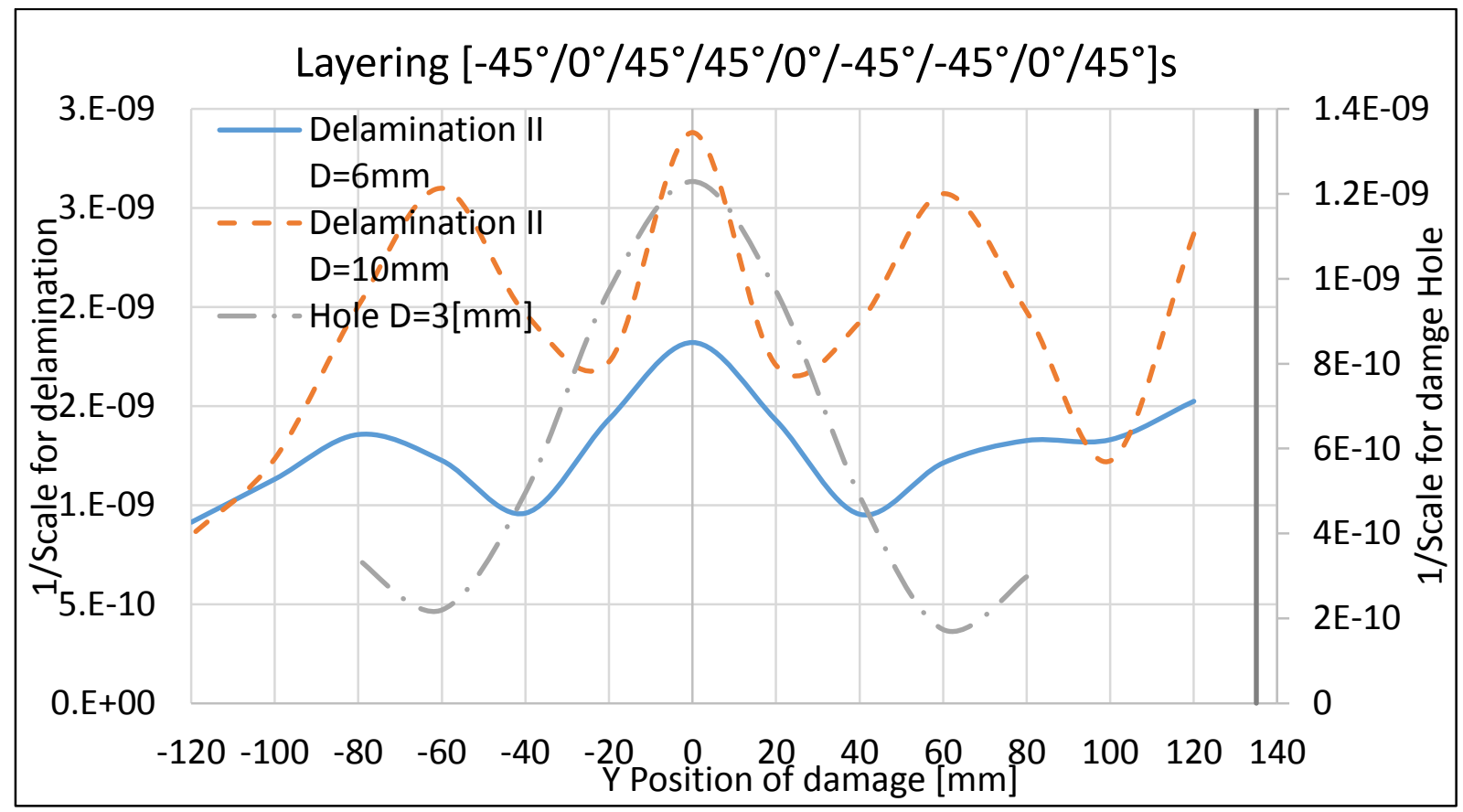

Figure 21: Comparison "1/scale" between hole and large delamination, layering Panel_45

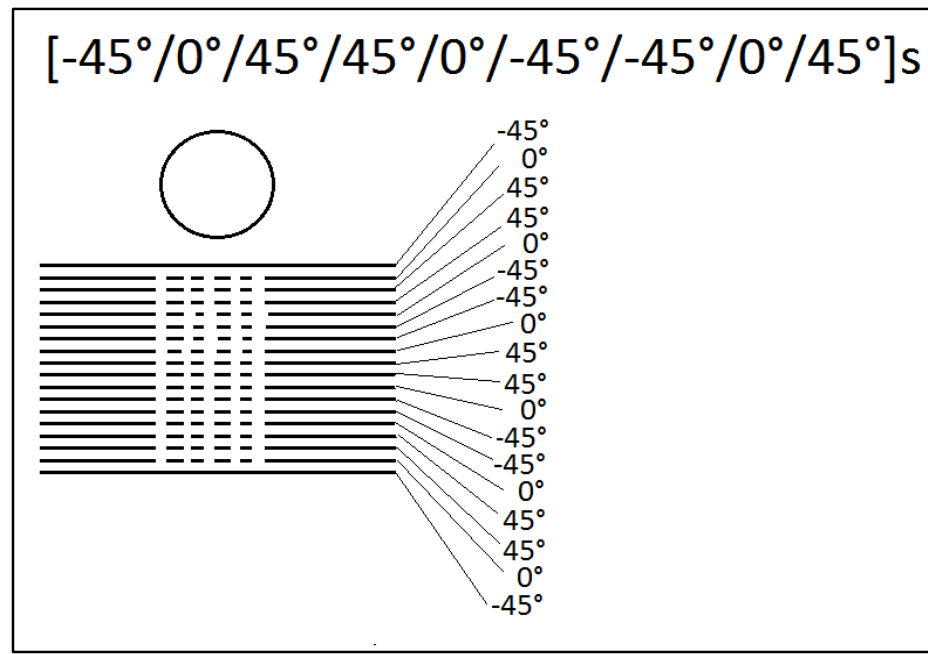

Figure 22: Large delamination, layering Panel_45

\subsection{Summary - Detection Areas}

This chapter summarizes the knowledge on sensor detection areas, which was received during UGW simulation using FEM. The simulated damage modes were: Panel damage - hole and delamination.

Biggest attention was paid to "hole" damage, where sensor detection area was defined for two layouts $\left[0^{\circ}\right] 12$ and $\left[-45^{\circ} / 0^{\circ} / 45^{\circ} / 45^{\circ} / 0^{\circ} /-45^{\circ} /-45^{\circ} / 0^{\circ} / 45^{\circ}\right]$ s. Detection areas are shown on Fig. 15 and Fig. 16. Graphs clearly show, that for unidirectional fibre layup $\left[0^{\circ}\right] 12$ with fibres in the direction actuatorsensor, detection area is on the line actuator-sensor. For quasi-isotropic fibre layup [$\left.45^{\circ} / 0^{\circ} / 45^{\circ} / 45^{\circ} / 0^{\circ} /-45^{\circ} /-45^{\circ} / 0^{\circ} / 45^{\circ}\right] \mathrm{s}$, the detection area is significantly more complicated, and it can spread to several areas.

For delamination, detection area for panel damage was checked only on the cut perpendicular to the line actuator-sensor, see Fig. 17 and Fig. 18. These cuts offer a similar result as for "hole" type of failure, see Fig. 19. For unidirectional composite material detection area is on the line actuator-sensor, for 
quasi-isotropic layup $\left[-45^{\circ} / 0^{\circ} / 45^{\circ} / 45^{\circ} / 0^{\circ} /-45^{\circ} /-45^{\circ} / 0^{\circ} / 45^{\circ}\right] \mathrm{s}$ the detection area is significantly more complicated, and it can spread to several directions.

Performed FE simulations show possibilities for evaluation of sensor detection areas. Detection areas are necessary for optimum sensor coverage on the panel (max. detection size with min. number of sensors).

\section{CONCLUSIONS}

The paper is focused on the simulation of ultrasonic guided waves (UGW) using commercially available finite element software packages (MSC.Patran/MSC.Dytran). UGW are considered for application in perspective SHM (Structural Health Monitoring) systems for aerospace applications. Such future SHM systems with sets of sensors integrated directly in the structure can bring significant advantages, such as savings in maintenance costs (less visual inspections), early identification of structural failures, etc. To support development of described future SHM systems, FE methods were applied with the target to simulate propagation of UGW in typical aerospace structures and estimate detection areas for PZT sensors.

The first set of presented simulations shows the potential of FE methods with 2D element models representing aerospace structure and 3D element models representing sensors. Furthermore, it shows the practical application of a sensor set on both sides of the panel, to identify symmetric and antisymmetric waves, see Fig. 5. Comparison of performed FE simulations with "analytical solution" (represented by "LAMSS - WAVEFORM REVEALER 3") shows an excellent agreement, see Fig.6 and Fig.7.

The last set of simulations present a method for identification of detection areas using FE simulation. This part is potentially the most valuable for future use. The ability to identify detection areas of sensors well before production of aerospace structures helps to properly design sensor sets for SHM on the designed structure. FE simulations again used 2D elements for the panel and 3D elements for sensors. The panel was all-composite with sensors and layering $\left[0^{\circ}\right] 12$ - PANEL_0 and [$\left.45^{\circ} / 0^{\circ} / 45^{\circ} / 45^{\circ} / 0^{\circ} /-45^{\circ} /-45^{\circ} / 0^{\circ} / 45^{\circ}\right] \mathrm{s}$ - PANEL_45. Basic simulated damage was hole ( $3 \mathrm{~mm}$ diameter) and delamination ( 6 and $10 \mathrm{~mm}$ diameter). Failure of "hole type" was analysed into higher detail with identification of detection areas on the panel shown on Fig.15. Resulting detection areas are shown on Fig. 15 and Fig. 16. For failure type "delamination" were identified only curves in "perpendicular cut-set", see Fig. 17. Results are presented on Fig. 18 and Fig. 20. Results indicate that unidirectional layering option $\left(\left[0^{\circ}\right] 12\right.$ - PANEL_0) has narrow detection area in the direction of line connecting sensors. Quasi-isotropic layering option ([-45\% $\left./ 0^{\circ} / 45^{\circ} / 45^{\circ} / 0^{\circ} /-45^{\circ} /-45^{\circ} / 0^{\circ} / 45^{\circ}\right]$ s - PANEL_45) has complex detection area, which can be split into several directions.

The performed activities clearly show the potential of FE codes to simulate the UGW signal in composite panels. Furthermore, interaction between UGW signal and failures (damage) was also shown and possibilities for identification of detection areas were demonstrated. Future activities will include detailed laboratory test to validate FEM. Knowledge of detection areas is a key prerequisite for practical design of SHM systems for future aerospace structures. It enables the placement of SHM sensors in optimum matter, therefore the design of low-weight aerospace structures with minimum sensors. Presented procedures enable practical design of SHM equipped aerospace structures with different geometrical and layering/material options. 


\section{ACKNOWLEDGEMENT}

Work published in the paper was co-funded by Technology Agency of the Czech Republic, through the research project TE02000032 Advanced Aerostructures Research Centre.

\section{REFERENCES}

[1] Christian BOLLER \& Norbert MEYENDORF: State-of-the-Art in Structural Health Monitoring for Aeronautics, Proc. of Internat. Symposium on NDT in Aerospace, Fürth/Bavaria, Germany, December 3-5, 2008

[2] CHRISTIAN BOLLER: Structural Health Monitoring-A Design and Integration Issue, $1^{\text {st }}$ Asian Pacific Workshop on Structural Health Monitoring, Yokohama/Japan;

[3] Holford, Karen Margaret, et al. "Acoustic emission for monitoring aircraft structures." Proceedings of the Institution of Mechanical Engineers, Part G: Journal of Aerospace Engineering 223.5 (2009): 525-532.

[4] Hill, Eric V. K., and Christopher L. Rovik. "In-flight fatigue crack growth monitoring in a Cessna T303 Crusader vertical tail." Journal of Acoustic Emission 31.1 (2013).

[5] Helge Pfeiffer, Martine Wavers: Aircraft Integrated Structural Health Assessment - Structural Health Monitoring and its implementation within the European project AISHA; Aircraft Integrated Structural Health Assessment (AISHA) meeting, Leuven, Belgium, June 2007.

[6] Raffaella Di Sante: Fibre Optic Sensors for Structural Health Monitoring of Aircraft Composite Structures: Recent Advances and Applications; Sensors 2015, 15; doi:10.3390/s150818666

[7] http://www.me.sc.edu/Research/lamss/html/software.htm

[8] http://www.mscsoftware.com/

[9] http://www.noliac.com/products/actuators/plate-actuators/show/nac2002/

[10] http://www.noliac.com/products/materials/nce51/

[11] Mustofa N. Ahmed: A Study of Guided Ultrasonic Wave Propagation Characteristics in Thin Aluminium Plate for Damage Detection, The University of Toledo, May 2014

[12] Composite material handbook -17 (CMH-17 2G) volume 2, Polymer Matrix Composites: Materials Properties, March 2012, SAE International

[13] Alem, N., Perry, M. (1995): Design of Digital Low-pass Filters for Time- Domain Recursive Filtering of Impact Acceleration Signals. United States Army Aeromedical Research Laboratory, Report No. 95-13

\section{COPYRIGHT STATEMENT}

The authors confirm that they, and/or their company or organization, hold copyright on all of the original material included in this paper. The authors also confirm that they have obtained permission, from the copyright holder of any third party material included in this paper, to publish it as part of their paper. The authors confirm that they give permission, or have obtained permission from the copyright holder of this paper, for the publication and distribution of this paper as part of the READ 2018 proceedings.

This is an open access article distributed under the Creative Commons Attribution License which permits unrestricted use, distribution, and reproduction in any medium, provided the original work is properly cited. (CC BY 4.0). 